\title{
Measuring the Guest-Host Interaction: An Empirical Analysis for Sustainable Tourism Development in Sikkim
}

Prof. G. Anjaneya Swamy, Dr. Debasish Batabyal, Arnab Gantait

Contemporary Research and Practices in Tourism and Hospitality: With Special Focus on Accessibility. (Ed), Prof. Venkata Rao, Dr. Sibi George, P.K. Mohanty and Dr. Ravish Mathew, ISBN: 978-93-5273-110-7. 


\title{
Measuring the Guest-Host Interaction: An Empirical Analysis for Sustainable Tourism Development in Sikkim
}

\author{
Prof. G. Anjaneya Swamy ${ }^{1}$, Dr. Debasish Batabyal', Arnab Gantait ${ }^{3}$
}

Abstract

The conventional concept of destination development undermined the sustainable issues and its orientation. Later on, the confusion was not the adoption of sustainable development philosophy but its correct implication and application. Alpine State Sikkim is primarily known as an exotic, idyllic, multi-ethnic Indian hill station since 1975 with its distinct biogeographic and socio-cultural characteristics. Being one of the successful and mature alpine Indian States, tourism development in Sikkim needs research oriented efforts. Most of the empirical researches for sustainable destination development are revolving around 'demand and supply' aspects of tourism which seeks equilibrium or a sustainable inter-linkage as a part of solution. The present article is also dealing with an important socio-cultural relationship between guests and hosts exhibiting from the predominating tourism phenomenon and redirecting destination development with a sustainable orientation. A survey was conducted for the primary data in three different places viz. Gangtok, Namchi and Mangan to assess tourism development of the State. Two sets of different questionnaires are prepared for guests and hosts. All the data are processed with the help of relevant non-parametric tests.

\section{JEL Classification: E21, Q56, P41, P52}

Key Words: Destination, National Tourism Organization (NTO), District Tourism Organization, Competitive Cooperation, Human Development Index, Unique Selling Proportion (USP), DLC, FMCG Product, Per Capita Expenditure, Kruskal Wallis Test, Kendall's Coefficient of Concordance

\footnotetext{
${ }^{1}$ Professor, Department of Tourism Studies, Pondicherry University, Email: anjaneya.dts@ pondiuni.edu.in

${ }^{2}$ Assistant Professor, Amity Institute of Travel \& Tourism Management, Kolkata, Email: debasishbatabyal@gmail.com

${ }^{3}$ Research Scholar, Dept. of Tourism Studies, Pondicherry University, Email: arnab8376@ gmail.com
} 


\section{Introduction}

The small hilly state Sikkim is encompassed by vast stretches of Tibetan plateau in the North, Darjeeling (West Bengal) in the south, the Chumbi Valley \& the kingdom Bhutan in the east and the kingdom of Nepal in the west and it lies between $27^{\circ} 04^{\prime} 46$ " $\mathrm{N}$ and $28^{\circ} 07^{\prime} 48^{\prime \prime} \mathrm{N}$ and $88^{\circ} 00^{\prime} 58^{\prime \prime} \mathrm{E}$ and $88^{\circ} 55^{\prime} 25^{\prime \prime} \mathrm{E}$. In summer, the maximum temperature goes up to $28^{0} \mathrm{C}$ while in winter it falls down to $0^{0} \mathrm{C}$ and sometime even below. The temperature in the bottom of the valleys (up to 600 metres) situated at lower elevations, particularly during summers, are similar to the monsoon type of climate. The temperature starts falling between 600 metres and 2000 metres above sea level and the place enjoys cool temperature climatic conditions and further up (2000 metres to 3000 metres) it is cold temperate climate. Arctic type of climate is found above 5000 metres. Though the state covers a very small area of only 7096 sq. Km, its environmental, social and cultural diversities are always being admired by the outer world. The scenic valley forests, snow clad mountains, magnificent Buddhist culture, heritages and peace-loving people are considered as the main USPs to grab the attention of tourists towards this small hilly state every year. There are differences in opinion regarding the origin and meaning of the name 'Sikkim' as some scholars believe that the word Sikkim involves Nepalese dialect and it refers to a 'new place' and some opine that the term has been derived from a Sanskrit word that means 'mountain crest'. Initially when Sikkim was an independent state, it faced many invasions by its neighboring countries and the then king asked for help from the British India and later, being grateful he offered some of its region from his vast kingdom including Darjeeling to the British Government. Now in this $22^{\text {nd }}$ Indian State (joined Indian Union in 1975), over $81 \%$ of the total geographical area comes under the administrative managerial control of Ministry of Environment and Forest, Government of India. Tree covers over $45 \%$ of the total geographical area of the state and nearly $34 \%$ of the geographical area is set aside as Protected Area Network in the form of National Park and Wildlife Sanctuary. Sikkim is ecologically a fragile region. The state has rich biological diversity that includes over 5000 species of angiosperm (one third of the total national angiosperms). 
The basic statistics of flora and fauna are given here under.

Table 1: Flora and fauna of Sikkim

\begin{tabular}{|l|l|}
\hline Mammals & 144 species \\
\hline Birds & 550 species \\
\hline Butterflies and Moths & 650 species \\
\hline Reptiles & 33 species \\
\hline Frogs & 16 species \\
\hline Orchids & 550 species,95 Genera \\
\hline Rhododendrons & 36 species, 45 varieties \\
\hline Flowering Plants & Over 4000 species \\
\hline Ferns and Allies & 300 species \\
\hline Conifers & 9 species \\
\hline Medicinal plants & Not enumerated \\
\hline
\end{tabular}

Source: Economic Survey 2006-07, Govt. of Sikkim

Again this place has multi-ethnic communities as the people of Sikkim have ethnic diversity. The Bhutias came from Tibet, the Nepalese came from Nepal and the Lepchas were the aboriginal community. So the need for ecological, cultural, and social diversities is not only essential but imperative as well.

Table 2: Sikkim at a glance

\begin{tabular}{|l|l|}
\hline Area & 7096 sq.km. \\
\hline Population(2001 census) & 540493 \\
\hline Growth rate(1991-2001) & $32.98 \%$ \\
\hline Density per square km. & 76 \\
\hline Sex ratio( female per 1000 male) & 875 \\
\hline Literacy rate & $69.68 \%$ \\
Male & $76.73 \%$ \\
\hline
\end{tabular}




\begin{tabular}{|l|l|}
\hline Female & $61.46 \%$ \\
\hline Capital & Gangtok \\
\hline No. of districts & 4 \\
\hline Legislature & Unicameral \\
\hline Principal languages & Nepali, Lepcha, Limbu \\
\hline Assembly seats & 32 \\
\hline Lok Sabha seat & 1 \\
\hline Rajya Sabha seat & 1 \\
\hline Judiciary(name and location) & High court of Sikkim at Gangtok \\
\hline State day & May 16 \\
\hline
\end{tabular}

Source: Economic Survey 2006-07, Govt. of Sikkim

\section{Study of Literature}

The 'destination', an agglomeration of actors seen from the supply side, exists in a kind of strategically dependent place having inherent or built resources. This definition can be described as a pragmatic demarcation which is analogue to marketing practice. The commercial actors (the industry's) empirical documented co-operation/network describes another space which is connected to the production chain and which differs from firm to firm. The authoritative actors (such as NTOs, DTOs etc.) acting in space inside administrative boundaries perceive tourism with almost all stakeholders and strive to synchronize the interest of all involved in the process. The business-inspired conventional authors are convinced of the importance of the 'destination' as a key factor in tourism, a place containing actors who produce together a total product which is the answer to the destination imagery and a total experience. They convince that a destination is a variety of products satisfying the tourists demand and is identical to the tourists understanding of the place they are visiting. The authors from economics mention three central notions: attractions, facilities, and services. But not all of them differentiate between them; some take the destination as an attraction, where an attraction is defined as an agglomeration of experiences, facilities and services. Non-commercial attractions such 
as landscapes, townscapes, beaches etc. are mentioned, but not seriously analyzed. These authors in the field of tourism accept co-operation as a mean of production, but most of them do not analyze it in any depth. Marketing authors emphasized the collaborative approach and strategic linkages of tourism principals and how a "competitive cooperation" distinctively playing an important role in destination as a whole. The sociological literature is talking about 'images' which are experienced by interaction with the tourist. Such images, for instance, are landscapes and townscapes as a part of the cultural heritage. Facilities and services are noticed, but not analyzed as such. The cited empirical findings point out the same descriptions of content depending on whom has been interviewed - the tourists, the commercial actors or the formal organizations.

Liu et al. (1987) carried out a major study of resident perceptions of the impact of tourism on the environment in Hawaii, North Wales and Turkey. Residents of Hawaii and North Wales gave protection of the environment the highest priority. It was ranked higher than cultural benefits, social costs and even economic benefits. Conclusions drawn from the study were that the impact of tourism on the environment is of universal concern; different cultures view the ways environmental and negative impacts of tourism are perceived differently; destination communities perceive many of the benefits brought by tourism, such as the preservation of historic sites; and it is important to incorporate the perceptions of host communities when evaluating the effects of tourism development for planning purposes. General public participation in planning is important for a variety of reasons. They include gaining attitudes and perceptions of residents' views on their environment, tourism development, and community aspirations and on the tourists themselves.

Dasmann et al. (1973: 115) suggested that 'the more local people benefit from tourism, the more they will benefit from a commitment to preserve the environmental features which attract tourism'. A second reason for community consultation is because not all communities are in favour of tourism development. Therefore tourism planning should always be carried out in close collaboration with the local inhabitants who are most likely to be affected. Kadt (1979) lamented that he knew of no country that 
evaluated alternative approaches to tourism for the purpose of selecting one that promised to maximize social benefits to hosts. He recommended community controlled, forwardlooking planning as opposed to typical remedial planning. This view was further strengthened by Murphy (1985) and Getz (1986) as they echoed the emphasis on community participation for its own gain. A third reason for community consultation is because it is the local people who have much to lose or gain from policy decisions. UNEP (1986: 2) suggested that 'tourism planning should always be carried out in close collaboration with the local inhabitants who are most likely to be affected'. Murphy (1983) asserted that tourism thrives on a community's resources and therefore it must take into consideration the opinions of the residents of a destination area. He added that there is a growing awareness of tourism's dependency on and responsibility to the local community. Consequently it is advocated that future planning be undertaken from the perspective of a community industry, one that is responsible to the community it is selling. This is also endorsed by Getz (1986), who suggested that a tourism development plan should include statements on what tourism is expected to contribute to more general goals including community development, enhancement of cultural identity, social welfare, the provision of leisure opportunities, as well as the provision and maintenance of living amenities.

The fourth aspect of gaining community views during the planning process is to gauge the perceptions of hosts (residents) to guests (tourists). Mathieson and Wall (1982) suggested that planners should consider the conflicting opinions of members of the community, and Romeril (1989) asserted that destination cultures vary in their degree of robustness or resilience to the impact of tourists. Many individuals involved in the tourist industry are likely to welcome tourists, whereas others may resent their presence and behavior. Drumm (1998) pointed out that host communities consider ecotourism as an accessible development alternative that can uplift their standard of living without having to sell off their natural resources or compromise their culture. In the absence of other sustainable alternatives, their involvement in ecotourism is often perceived as the best option for achieving their aspiration of sustainable development. Drumm (1998) outlined a number of options for communities wanting to become involved in tourism 
development. These include (i) renting land to an operator to develop while simply monitoring impacts, (ii) working as occasional part-time or full-time staff members for outside operators, (iii) Providing services such as food preparation, guiding, transport or accommodation to operators, (iv) forming joint ventures with outside operators with a division of labour, which allows the community to provide most services, while the operator takes care of marketing, (v) Operating fully independent community tourism programmes. He further stated that in each case, full community involvement in all stages of planning and management is essential to ensure healthy development.

In most of the current literature tourism's impacts on the physical environment have been seen in a negative light. Wall (1994) notes that ecotourism attracts attention to natural treasures, thereby increasing the pressures upon them. Hvenegaard (1994) describes a number of adverse environmental impacts caused by tourism. They include overcrowding, overdevelopment, unregulated recreation, pollution, wildlife disturbances and vehicle use. However, the positive benefits of the environment-tourism relationship have also been considered for over three decades. Tourism and the environment are interrelated and it is argued that there are a number of reasons why conservation should seek the support of tourism. These include the fact that tourism provides conservation with an economic justification, it is a means of building support for conservation, and it can bring in resources for conservation (Phillips, 1985). In fact, economic impacts may be measured and quantified to identify financial and employment effects, social and cultural impacts on visitors and host communities are often only considered when tourism development leads to local opposition (Page and Dowling, 2002). The attitudes of a host community's residents are a key component in identifying, measuring and analyzing the impact of tourism. Resident perceptions of tourism may be one factor in shaping the attractiveness of a destination, and negative attitudes may be one indicator of an area's ability (or inability) to absorb tourism.

Doxey's (1975) Index of Tourist Irritation (Irridex) illustrates how the interaction of tourists and residents may be converted into different degrees of irritation. He argued that residents' responses would change in a predictable manner, passing through four 
stages - euphoria, apathy, annoyance and antagonism. However, at any one point in time, a community will be characterized by a range of views and grouping them into a simplified model such as Doxey's does not recognize local diversity (Page and Dowling, 2002). The socio-cultural environment also serves as both an attraction and a recipient of tourism's impacts on host communities (Lindberg and McKercher, 1997). If the impacts become adverse the sustainability of local tourism will be in danger. For the tourism industry, the main concerns are to ensure the local population are not alienated or adversely impacted to the point that they may want to affect the local resource base or deny future access to the resource, over which they are the custodians.

One of the key elements of tourism is that it should be beneficial, which also raises issues related to the degree of control local people have over ecotourism ventures, highlighting the need to consider the empowerment of local communities (Ashley and Roe, 1998; Scheyvens, 1999). If positive attitudes to tourism are to be fostered, then destination communities should receive economic and social benefits. These include improved cultural appreciation and understanding, cultural heritage, and local pride (Ross and Wall, 1999). It is also important that local residents decide what level of tourism they want (i.e. self-determination), what cultural practices they wish to share, and where tourists will be allowed to go. Several levels of involvement are possible, from full community development of facilities, to partnerships or joint ventures with the industry (Brandon, 1996). The process should include raising the awareness of probable tourism impacts so that residents can make informed decisions regarding the desirability of tourism. Thus tourism development should only be considered successful if local communities have some measure of control over it and if they share equitably in the benefits emerging from ecotourism activities (Scheyvens, 1999).

In their article 'Adaptation and development: Livelihoods and climate change in Subarnabad, Bangladesh', Pouliotte J., Smith B. \& Westerhoff L. (2009) explored the relationship between environmental change and development through a vulnerability study of a rural village in southwest Bangladesh. Here, villagers dealt with a variety of pressing stresses and climate change is not considered separately, if at all. All 
the environmental, political and economic conditions and adjustments in resource use systems, particularly shrimp farming, changed livelihood opportunities and increased the vulnerabilities of poor villagers to future environmental changes, including climate change. Practical adaptation strategies to reduce vulnerabilities to climate-related stresses reflected the dynamics of people's livelihoods and address the conditions they currently face. In this case, planned adaptations were mainstreamed in the sense that they contributed to the livelihoods of people and made some improvement in their capacity to deal with changes in climate, and they were undertaken via established non-government institutions.

In the article 'Poverty, Indigenous Culture and Ecotourism in Remote Australia', Fuller, D. Caldicott J. Cairncross G. \& Wilde S. ( 2007) found significant challenges to be existing for indigenous people in identifying suitable economic and commercial development opportunities directed at enhancing economic and human development within their communities. Ecotourism was seen as one sector that could provide such opportunities there. The authors examined the importance and implications of indigenous culture for ecotourism developments in that remote Australian indigenous communities, in order to evaluate the potential of ecotourism ventures as a possible contributor to economic and human development within remote indigenous communities. In addition to examining the influence of culture, this paper suggested the important strategies for indigenous success in operating ecotourism enterprises including the importance of consultation and planning processes, the availability of suitable education and training to indigenous business owner-operators and the availability of joint-venture partnerships with actors in the mainstream economy.

McIntosh specified the following goals essentially revolving around the benefits to the local communities. These are (i) to maintain the traditional pattern of agriculture, (ii) to encourage those forms of tourism with the greatest local benefit, (iii) to create jobs at most of the existing settlements within the region, and (iv) to safeguard the identity of local communities by seeking to retain and develop cultural heritage. Sikkim will have a competitive advantage if the local communities are involved from planning and administration to its actual implementation. 


\section{Purpose of the study, Methodology and Hypothesis}

The basic purpose of the study is to assess the traditionally accepted guest-host relationship with sustainable destination development and management perspective. The relationship between guest and host has several new innovative implications in destination development and its management. Here, we find a new approach of destination development with an understanding of sociological relationship contributing to the introduction and management of human resources involved in tourism as local community, industry personnel and tourists. It will also introduce an initiative to adopt a sustainable development of all destination stakeholders. More specifically, the main objective of the study is

- To identify and measure the relationship between the intensity of tourists and adverse and positive socio-cultural and economic impacts of tourism equally.

This study is conducted by using self-administered questionnaires with the consent from the Hotel managers beforehand. Pilot testing was conducted using a small convenience sample of 35 respondents from various hotels in Sikkim. The respondents were informed that their participation was on a voluntary basis and all information provided would be kept private and confidential. Questionnaires were circulated only to those who showed interest towards the study. The nature and requirement of the survey were briefly explained before the respondents filled up the questionnaire. For collecting the primary data, two sets of structured questionnaire were made, one for tourists and another for community members belonging to Gangtok, Namchi, Mangan, and Pelling. Apart from observation, schedules and interview methods were followed for the above said purpose. A total of 475 customers were interviewed, and the overall response rate was $42.32 \%$ (201 completed, usable questionnaires). A total of 480 Community members of the different areas of Sikkim were contacted and the overall response rate was $20.41 \%$ (98 completed, usable questionnaires). 
Besides, Economic Review of Sikkim (2006-2007), Human Development Report of Sikkim (2001), Report of the TATA Economic Consultancy on Tourism, various articles, journals etc. have been considered as secondary data source.

Ho: There is no relationship between the intensity of tourists (or its number of arrivals) and its consequent tourism impacts

\section{Study of Local Community and Tourists}

Sikkim has a total population of 540851 (according to the 2001 Census) of which $47 \%$ are female. The social compositions (ethnical group) of Sikkim are - Lepcha (19\%), Bhutia (16\%) and Nepali (56\%) which constitutes a majority of the population. The Measurement of Human Resource has put Sikkim among the top of all the small States of India, which has brought home a National recognition Award on 6th August 2004, in a conclave of Chief Minister held at New Delhi. In the category of small states, Sikkim is one of the best performing states in the field of law and order, health and investment scenario while, secured the topmost rank in the field of education. After merging with India, Sikkim has recorded several significant gains in the human development indicators. According to Human Development Index, women of this state have been given special place in GDI (Gender Development Index) and GEM (Gender Empowerment Measures) calculations. Women also enjoy many freedoms and have recorded significant gains in the race of overall human development. However, like in many parts of the globe, they still live in an unequal world. In Sikkim, women enjoy relatively greater freedom than in other parts of the country. Communities, cultures, religions and customs of different hues intermingle freely here in Sikkim, to constitute a homogeneous blend. Hindu temples coexist with Buddhist monasteries, a few Christian churches, Muslim mosques and Sikh Gurudwaras. The predominant communities are the Lepchas, Bhutias and Nepalese, Women attributes high Position in the society. In the urban areas Marwaries, Biharis, Bengalees, South Indians and Punjabis have also settled who are mostly engaged in business and government services. Cultural and economic forces boosted by the information technology and development activities are reshaping 
the way of life of the citizen of Sikkim. The people of Sikkim have however proved to be resilient, accepting the benefits of progress while retaining their ethnic identity.

After becoming $22^{\text {nd }}$ state of the Union Government of India in the year 1975 the rapid development activities ushered in a new era of tourism in Sikkim. Increased accessibility by roadways and air transport, rapid socio-economic development, competitive advantage both from the side of the destination and geographical proximity to tourist generating states contributed to the development of tourism in Sikkim. Recognizing the increased tourist arrivals, accommodation units were set up in Gangtok and a few towns mostly by outsiders without proper land use planning and architectural design. (Batabyal D. 2014)

\section{Figure 1: Domestic and Foreign Tourist Arrivals in Sikkim}

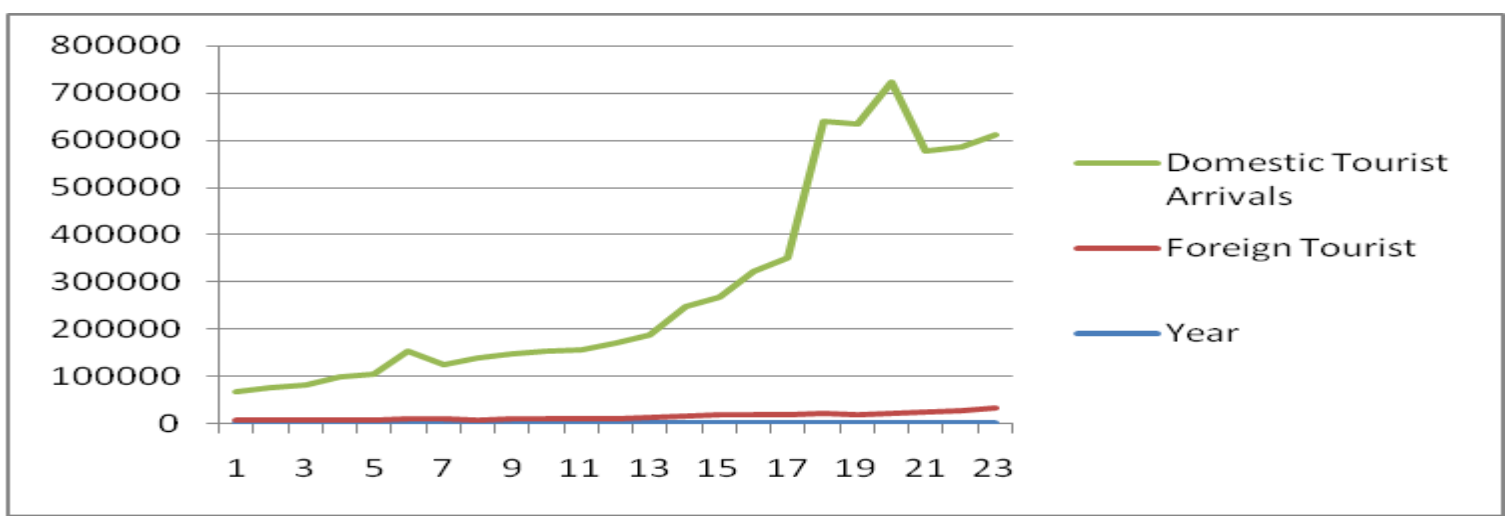

Source: Sikkim Tourism Development Corporation, 2014

Arrival statistics of domestic and international tourists for last 23 years (since 1991) has clearly indicated the dominant position of domestic tourism compared to its foreign tourist arrivals. The consequent effects of earthquake for two consecutive years of 2011 and 2012 resulted in a down fall and even a negative growth in overall arrivals in Sikkim. 
Following the case studies of Sikkim over the years it has been noticed that all destinations at each life cycle stage are characterized with specified attributes. The most succinct views related to destination development have been given here under.

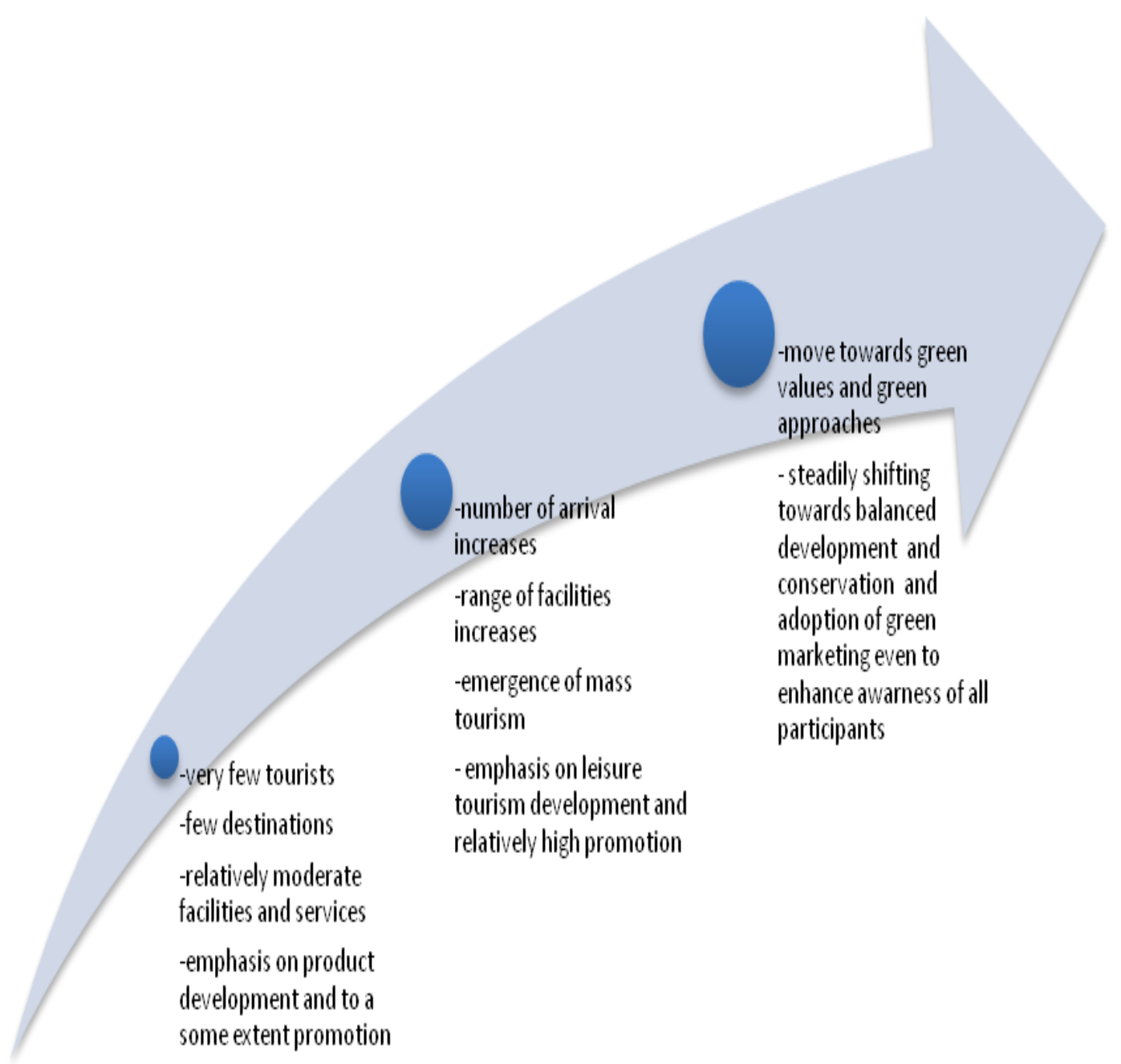

\section{Figure 2: Changes in destination development approaches of Sikkim since 1975}

Development and adoption of marketing approach extensively include a 'demand -supply equilibrium' and as such takes into account tourism system. Destination marketing is unlike a marketing of FMCG products as it considers and more towards services. Again, in many cases the adoption and control is not fully devolved upon 
corporate sectors. As a service marketing it includes customer relationship management, internal marketing (with respect to a destination where all stakeholders are part of the product and contribute to the image and identity), increased importance of strategic alliances/ linkage etc. Though destination management concept should include destination marketing but in Indian context very often management and marketing are wrongly conglomerated with each other. Very few Indian destinations are well managed by scientific research and background analysis. It is sorry to say that Sikkim has poor quality database and only in few cases the available data have been scientifically analyzed and interpreted as unfortunately, majority of the government officials who are also the destination planners have no tourism background. So, an understanding of the demand for Sikkim as a destination and the capacity levels (physical, biological, social, psychological, financial) largely contribute to the overall marketing strategy (Batabyal, D., \& Mukherjee, S. K., 2016). The government of Sikkim is one of the very few Indian states those are trying to optimize benefits from tourism for their local community. The policies adopted to position the state as an Ultimate Ecotourism Destination was really a committed responsibility towards sustainable development. Next to this is rural tourism and adventure tourism. All these forms of tourism will contribute to the alternative tourism development in the state and the changes in types and forms of tourism will automatically have an impact on the activities of the tourists, duration of stay, the number of tourist arrivals and the tourism industry as a whole. A proactive environment friendly approach has already been adopted in the marketing mix and Unique Selling Proposition (USP) of Sikkim though there are many things remaining. The major task for the government is how to coordinate and control interest of all participants and infuse the idea of sustainable practices in the state. The priority area is really confusing as there is a traditional clash between development and conservation. The destination marketing should not only increase the arrival of tourists but also be proactive in selecting target groups and introduce sustainable practices including mass awareness for environmental conservation.

The majority of the income group of domestic tourists are found to be in the slab of Rs. 30000 above. The second important feature is the second largest number of 
respondents immediately preceding the earlier slab i.e. 20,001-30,000. It is also found that the segment of lower income group is interested to travel the traditionally known leisure tourist destination Sikkim. The majority of the income level of foreign tourists are found to be above Rs.1, 00000 and it is followed by 80,001 - 1,00000 and 60,001 80,000 respectively. Sikkim receives a considerable number of independent tourists even from the domestic segments and there is a new trend to avail of partial inclusive package of transportation and accommodation units only. Independent tourists don't book any facility or service in the destination a priori and can avail of all immediately after reach.

Figure 3: Types of Tour in Sikkim

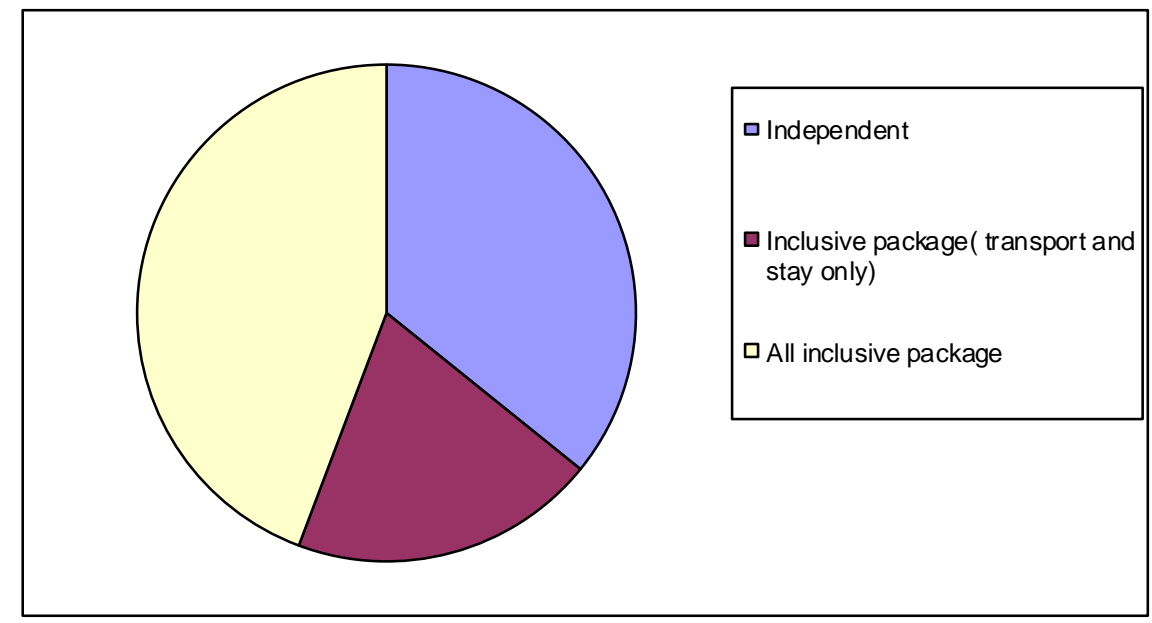

Source: Field Survey, 20013-2014

Majority of tourists travel Sikkim in group and avail of all inclusive tour packages till date. The above diagram expresses the further scope for measuring the involvement of tourism industry with recent changes. Sikkim is found to the destination of service holders who are associated either in public or private sectors in India or abroad. Second important occupational group is the businessmen who are self employed and traveling either with their family or for the core business purpose. Third group is either students or scholars or house wives. 


\section{Figure 4: Purpose of Visit in Sikkim by Domestic and Foreign Tourists}

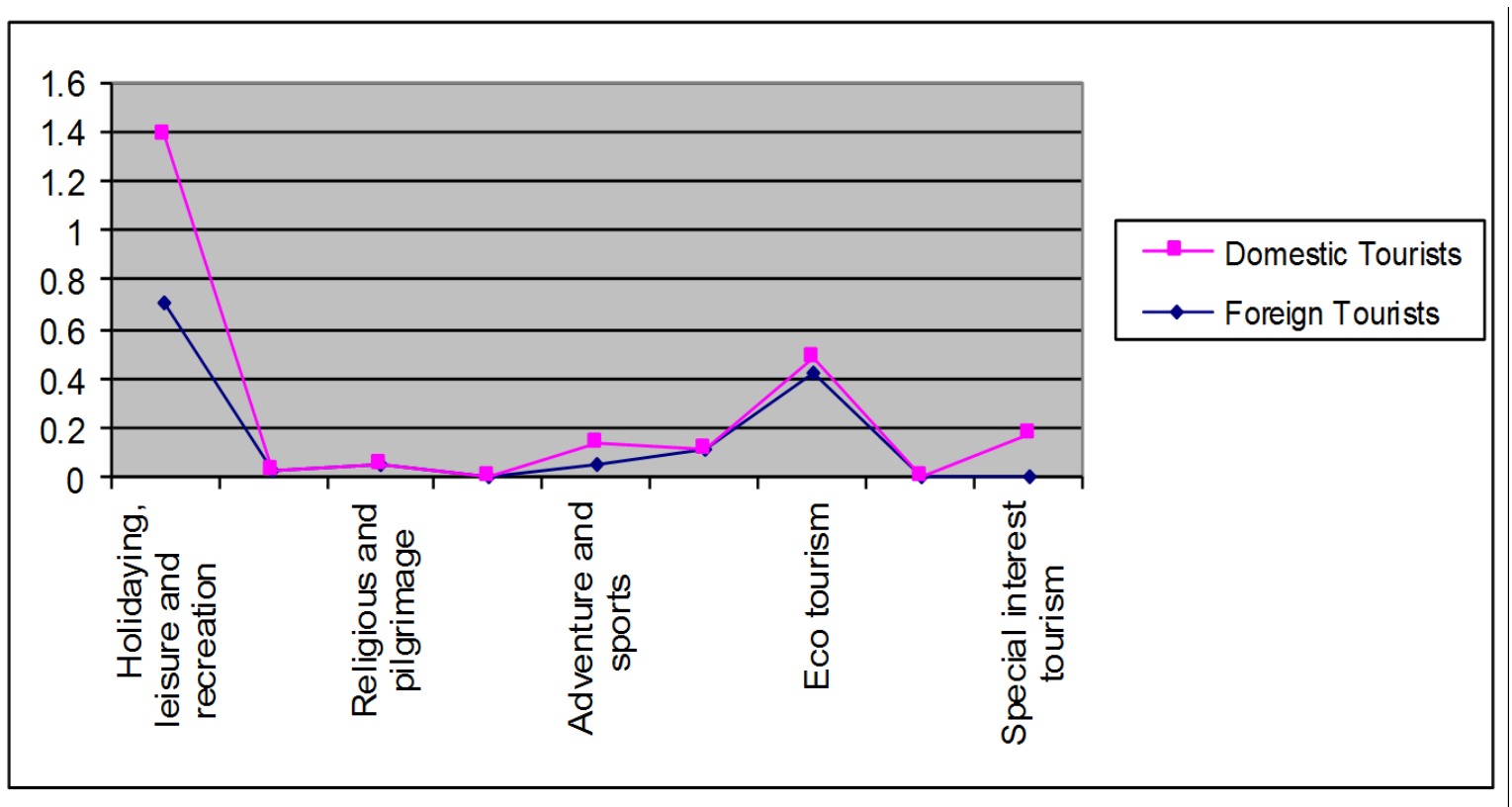

Source: Field Survey, 20013-2014

A general influx in either case of domestic and international tourists is found in case of ecotourism and to some extent adventure tourism. So, there is an immense growth potentiality for ecotourism, adventure tourism and special interest tourism. The market for special interest tourists has been growing more with the foreign counterparts. There is also a small influx in pilgrimage and Buddhist cultural affiliation. Through their present demographic characteristics and product choice, significant future requirements for infrastructure and superstructure are interpreted.

\section{Conclusion}

More than ninety per cent of the total number of tourists visiting Sikkim is domestic and rests are international. So, domestic tourists are pre-dominating the guesthost relationship. Foreign tourists, though small in size, are distinctive, identifiable and creating high socio-cultural and economic impacts as their level of involvement was 
found to be high. Keeping in view the proportion of arrivals of either type of tourists, questionnaires for tourists was surveyed specifically to know why they travel.

Table 3: Mean of Ranks* Showing the Purposes of Travel

\begin{tabular}{|l|l|l|l|l|l|l|}
\hline \multirow{2}{*}{ Factor } & \multicolumn{2}{l|}{ All tourists } & \multicolumn{2}{l|}{ Domestic Tourists } & \multicolumn{2}{l|}{ Foreign Tourists } \\
\cline { 2 - 7 } & $\begin{array}{l}\text { Mean of } \\
\text { Ranks }\end{array}$ & Ranks & $\begin{array}{l}\text { Mean of } \\
\text { Ranks }\end{array}$ & Ranks & $\begin{array}{l}\text { Mean of } \\
\text { Ranks }\end{array}$ & Ranks \\
\hline $\begin{array}{l}\text { Holidaying, leisure and } \\
\text { recreation }\end{array}$ & 1.64 & 1 & 1.49 & 1 & 3.09 & 2 \\
\hline $\begin{array}{l}\text { Social (visiting friends and } \\
\text { relatives, marriage etc.) }\end{array}$ & 5.89 & 8 & 5.71 & 7 & 7.28 & 8 \\
\hline Religious and pilgrimage & 5.82 & 7 & 5.79 & 8 & 5.84 & 6 \\
\hline Adventure and sports & 4.17 & 4 & 4.35 & 4 & 3.13 & 3 \\
\hline $\begin{array}{l}\text { Providing holiday } \\
\text { opportunity to spouse/ } \\
\text { family/attendant }\end{array}$ & 4.11 & 3 & 3.76 & 2 & 6.30 & 7 \\
\hline Eco tourism & & & & & & \\
\hline Rural tourism & 3.89 & 2 & 4.06 & 3 & 3.19 & 4 \\
\hline Special interest & 5.47 & 6 & 5.54 & 6 & 4.28 & 5 \\
\hline
\end{tabular}

* Mean of Ranks derived from Kendall's Coefficient of Concordance

The mean of ranks ultimately exhibits the ranks to be considered to know why people travel. Each purpose separately contributes as the type and form of tourism contribute largely to destination development and management strategy. Domestic tourists are largely responsible for domestically institutionalized forms of tourism development typically oriented to cheap tourist products, more price sensitivity, tourist arrivals along a very few tourist circuits resulting in deterioration of environment and ecology. Again, from all ranks, it is expected that foreign tourists will induce high impact tourism with more involvement that may result in serious cultural and ecological damage and less amount of economic benefits with a handful of tourists. So, there is an ambiguity 
as to how to increase per capita expenditure without ecological deterioration. From the supply side aspects, initiatives and allotment of infrastructure and superstructure development is also heavily influenced by the above mean ranks.

Another primary data survey, specifically to verify hosts' opinion, brought to light a new orientation of supply side aspects of tourism. Households in Sikkim are asked to explain their agreement with respect to the thirty one most important interrelated and interdependent industry and/or impact variables with the appropriate scale (strongly disagree $=1$, strongly agree $=5$ ). When households in Sikkim are asked to explain their agreement with respect to these thirty one most important interrelated and interdependent statements of tourism industry/ impact variables with the appropriate scale (strongly disagree $=1$, strongly agree $=5$ ), a typical orientation of destination specific and prevalent variables came to light. The above thirty one variables are taken into note by considering the most noticeable adverse impact variables of tourism in most of the Indian alpine regions. More specifically, hosts in Gangtok are agreed or strongly agreed upon most of the industry and/or impact variables while hosts in Namchi and Mangan considered less number of industry and/or impact variables as tourism, so far, is less intensive compared to Gangtok. The most prevalent Kruskal Wallis rank test has exhibited .002 (asymp. Sig) for Gangtok while the same is 0.00 for all three destinations. Gangtok is having an institutionalized form of tourism development with high tourist intensity, retention and inadequate or inappropriate or absence of tourism legislation (Butler Classical Model for different types of tourism legislation). This institutionalized form of tourism has an influence on the tourist satisfaction and sustainability factors.

Another non-parametric Kruskal Wallies rank test for fifteen most important and noticeable impact variables with five point scale is indicating adverse effects of tourism, has exhibited the same indication of regional disparity i.e. destination specific importance of all such variables. A total ninety eight questionnaires are surveyed in three different places of Gangtok, Mangan and Namchi. The rank indicated a very significant result of .000 for all three places while for Gangtok, Namchi and Mangan the results were .981, .146 and .726 respectively. The results are given here under. 
Table 4: Results of Industry and/or Impact Variables Showing Regional Disparity

\begin{tabular}{|c|c|c|c|}
\hline Sikkim & Gangtok & Namchi & Mangan \\
\hline Test Statistics & Test Statistics & Test Statistics & Test Statistics \\
\hline VAR00001 & VAR00001 & VAR00001 & VAR00001 \\
\hline Chi- $\quad 512.818$ & 22.158 & 37.005 & Chi- $\quad 24.050$ \\
\hline Square & Square & Square & Square \\
\hline df $\quad 98$ & df $\quad 38$ & df $\quad 29$ & df $\quad 29$ \\
\hline Asymp..000 & Asymp. .981 & Asymp. .146 & Asymp..726 \\
\hline Sig. & Sig. & Sig. & Sig. \\
\hline a Kruskal Wallis & a Kruskal Wallis & a Kruskal Wallis & a Kruskal Wallis \\
\hline Test & Test & Test & Test \\
\hline b Grouping & b Grouping Variable: & b Grouping Variable: & b Grouping \\
\hline Variable: & VAR00002 & VAR00002 & Variable: \\
\hline VAR00002 & & & VAR00002 \\
\hline
\end{tabular}

A distinct and surprising result is that more the mass tourists of Gangtok are satisfied less the local community is likely to be happy. This event contradicts the conventional belief of interrelated and interdependent satisfaction between guest and host or may be the earlier stage where the interests of all the parties are protected. Though the information of the number of tourists visiting Sikkim is available, yet the concept of collecting region specific information is not in vogue. Again, the supply side aspects of each destination is different and not to be confused by considering apparently similar attraction features and infrastructural requirements. It implies relatively a high degree of impacts (favorable and unfavorable) and their increasing awareness among the local 
people. It also implies a variation of opinion influenced by a region and its distinct economic, environmental and socio-cultural issues.

More specifically, following are the issues to be considered as a part of sustainable destination development with an emphasis on economic and socio-cultural relationship between guest and host in Sikkim.

- Development of similar attraction features keeping in mind the channelizing of similar tourist traffic.

- Advertisement efforts should penetrate all such destinations

- Zoning and architectural design, development of new circuits, possible adventure/ alternative/ special interest tourism potentialities should be a part of proactive destination development program (DDP).

- More financial incentives and less fiscal control to be the basis of drawing the interest of investors with an emphasis of local entrepreneurship development.

A holistic orientation of tourism among all authorities, inclusion of all other government and non-governmental agencies, development of supply linkage, changes in demand orientation are required. It is also the recommendation for destination specific development directed to the optimization of achieving equilibrium of interest for all stakeholders in which local people are predominating.

\section{References}

$\checkmark$ Ap, J., \& Crompton, J. L. (1993). Residents' strategies for responding to tourism impacts. Journal of travel research, 32(1), 47-50.

$\checkmark$ Ashworth, G. and Goodall, B., (1991), Marketing Tourism Places, Routledge, London.

$\checkmark$ Bærenholdt, J.O, Framke, W., Nilsson, P.Å. (1999): Destination construction and development - Representations, networks and strategies. Paper. Roskilde University

$\checkmark$ Bærenholdt, J.O. (2000): Revised research design on the project: Destination construction and development - Representations, networks and strategies. Paper. Roskilde University 
$\checkmark$ Bagri, S.C., (2003), "Trends in Tourism Promotion (Emerging Issues)" , Himalayan Eco Tourism Society ( Sri Nagar, Garhwal) and Bishen Singh Mahendra Pal Singh ( 23-A Connaught Place, Dehradun).

$\checkmark$ Batabyal, D., \& Mukherjee, S. K. (2016), Elitist Tag or Tool for Development: An Empirical Analysis for Tourism. Handbook of Research on Promotional Strategies and Consumer Influence in the Service Sector, 96.

$\checkmark$ Butler, R.W. (1980), 'The Concept of the tourist area cycle of evolution: Implementations for management of resources', Canadian Geographer, Vol. 24, p.5-12

$\checkmark$ Chettri N., Sharma E., Deb D.C., Sundriyal R.C. Impacts of Firewood Extraction on Tree Structure, Regeneration and Woody Biomass Productivity in a Trekking Corridor of the Sikkim Himalaya', 'Mountain Research and Development', Vol.22,May 2002, pp. 150-158.

$\checkmark$ Diamond J. (2008). Tourism's Role in Economic Development: The Case Reexamined. Economic Development and Cultural Change. Vol. 25, No. 3. (Apr., 1977). pp. 539-553

$\checkmark$ Dixit Saurab Kumar (2005). Aspects of Tourism Development. 1st Edition, Mohit Publications. New Delhi.

$\checkmark$ Doswell Roger (1997). Tourism: How effective management makes the difference. $1^{\text {st }}$ Edition. Butterworth Heinemann. New Delhi.

$\checkmark$ Dowling, R. K. (1993). Tourism planning, people and the environment in Western Australia. Journal of Travel Research, 31(4), 52-58.

$\checkmark$ Dowling, R. K. (2003). Community Attitudes: Tourism 11 Development in Natural Environments. Tourism in destination communities, 205.

$\checkmark$ Economic Survey 2006-07, Govt. of Sikkim, India

$\checkmark$ Envis Team, "Eco-destination of India: Sikkim Chapter", Envis Centre Sikkim on Ecotourism.

$\checkmark$ Evans N., Campbell D. and Stonehouse G. (2007), "Strategic Management for Travel and Tourism", Butterworth and Heinemann, New York.

$\checkmark$ Getz, D. (1986). Models in tourism planning: Towards integration of theory and practice. Tourism management, 7(1), 21-32.

$\checkmark$ Hashimoto A. (2002), 'Tourism and Socio-cultural Development

$\checkmark$ Higginbottom K and Scott N. 'Wildlife Tourism: A Strategic Destination Analysis', in Wildlife Tourism Impacts, Management and Planning( 2004) eds Karen Higginbottom , Common Ground Publishing Pty Ltd, Australia, p. 253277.

$\checkmark$ Higham J. (2007), eds, "Critical Issues in Ecotourism: Understanding a Complex Tourism Phenomenon", Elsevier Butterworth-Heinemann, Amsterdam.

$\checkmark$ Issues', in Sharpley R. and D.J. Telfer eds 'Aspects of Tourism: Tourism and Development, Concepts and Issues', Channel View Publication p.p. 202- 230, 
$\checkmark$ Karma, K.K. (2001), "Managing Tourist Destination: Development, Planning, Marketing, Policies", Kanishka Publishers, Distributors, New Delhi.

$\checkmark$ Leiper, N. (2000): Are Destinations 'The Heart of Tourism'? The advantages of an Alternative Description. Current Issues in Tourism, Vol.3, No.4

$\checkmark$ Mill, R.C. \& Morrison, A.M. (1992): The Tourism System. Englewood Cliffs

$\checkmark$ Murphy, P. (1985): Tourism. A Community Approach. New York

$\checkmark$ Pouliotte, J., Smit, B., \& Westerhoff, L. (2009). Adaptation and development: livelihoods and climate change in Subarnabad, Bangladesh. Climate and Development, 1(1), 31-46.

$\checkmark$ Rahman, S.A. (2006), Editor in Chief, "The Beautiful India- Sikkim”, Reference Press, New Delhi

$\checkmark$ Sutheesna Babu. S, Sitikantha Mishra, Bivraj Bhusan Parida (2008), "Tourism Development Revisited: Concepts, Issues and Paradigms", edited, Sage Publications, ISBN: 978-81-7829-797-3.

$\checkmark$ Swarbrooke, J. \& Horner, S. (1999): Consumer Behavior in Tourism. Oxford

$\checkmark$ Swarbrooke, J. (2001): Organisation of tourism at the destination. In: Wahab, S. \& Cooper, C.: Tourism in the Age of Globalisation. London, 159-182 